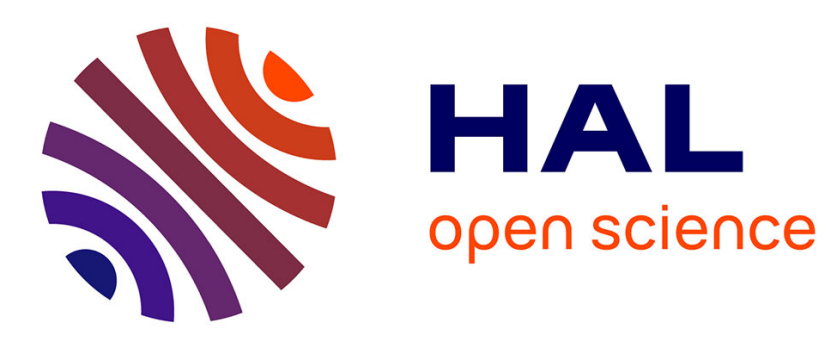

\title{
Site-selective spectroscopy of Pr3+ ions in sodium [MATH]-alumina crystals
}

\author{
G. Mariotto, F. Tietz, E. Zanghellini, M. Ferrari
}

\section{To cite this version:}

G. Mariotto, F. Tietz, E. Zanghellini, M. Ferrari. Site-selective spectroscopy of Pr3+ ions in sodium [MATH]-alumina crystals. Journal de Physique IV Proceedings, 1994, 04 (C4), pp.C4-473-C4-476. 10.1051/jp4:19944113 . jpa-00252563

\section{HAL Id: jpa-00252563 https://hal.science/jpa-00252563}

Submitted on 1 Jan 1994

HAL is a multi-disciplinary open access archive for the deposit and dissemination of scientific research documents, whether they are published or not. The documents may come from teaching and research institutions in France or abroad, or from public or private research centers.
L'archive ouverte pluridisciplinaire HAL, est destinée au dépôt et à la diffusion de documents scientifiques de niveau recherche, publiés ou non, émanant des établissements d'enseignement et de recherche français ou étrangers, des laboratoires publics ou privés. 


\title{
Site-selective spectroscopy of $\operatorname{Pr}^{3+}$ ions in sodium $\beta$-alumina crystals
}

\author{
G. MARIOTTO, F. TIETZ, E. ZANGHELLINI and M. FERRARI* \\ Università di Trento, Dipartimento di Fisica, 38050 Povo (Trento), Italy \\ * Centro CNR di Fisica degli Stati Aggregati e Impianto Ionico, 38050 Povo (Trento), Italy
}

\begin{abstract}
We report on the results of a low-temperature optical spectroscopy study of $\mathrm{Pr}^{3+}$-exchanged sodium $\beta$-alumina single crystals $\left(\mathrm{Na}^{+} / \mathrm{Pr}^{3+} \beta-\right.$ $\mathrm{Al}_{2} \mathrm{O}_{3}$ ), containing different amounts of luminescent ions, in which excitation and fluorescence spectra have been carried out in $\sigma$ and $\pi$ polarization.

The ${ }^{3} \mathrm{P}_{0} \rightarrow{ }^{3} \mathrm{H}_{4}$ emission spectra, obtained under broad band excitation, show an intriguing structure consisting of several components even with crystals containing low $\mathrm{Pr}^{3+}$ concentrations. The excitation spectra indicate the presence of at least two sets of different sites, available to $\mathrm{Pr}^{3+}$ in the conduction plane of $\beta$-alumina. Independently of the crystal composition, a quite satisfactory site-selective emission from each sets of centres has been achieved under cw excitation of the $465.8 \mathrm{~nm}$ and $476.5 \mathrm{~nm}$ lines of an $\mathrm{Ar}^{+}$ ion laser.
\end{abstract}

\section{Introduction}

The discovery that sodium $\beta "$-alumina, already well known as one of the most promising solid electrolyte, is able to incorporate a large variety of luminescent ions via ion-exchange reactions at moderate temperature prompted much interest in the possible optoelectronic applications of this material. During the last years, the optical properties of trivalent lanthanide ions in the sodium $\beta^{\prime \prime}$-alumina have been extensively investigated [1-3] and some compositions have been proved to lase [4]. Recently, we succeeded in exchanging lanthanide ions in sodium $\beta$-alumina [5], a structurally close related compound, thus obtaining a potential alternative laser material. Some highly exchanged $\mathrm{Na}^{+} / \mathrm{Pr}^{3+} \beta-\mathrm{Al}_{2} \mathrm{O}_{3}$ crystals have been preliminarly investigated by optical spectroscopy methods [6] with the aim to identify the type of sites occupied within the conduction planes of the host matrix. Indications about the existence of unequivalent sets of centres, characterized by different local environments, were derived from low-temperature measurements of either excitation spectra or time-resolved fluorescence of the ${ }^{3} \mathrm{P}_{0} \rightarrow{ }^{3} \mathrm{H}_{4}$ transition of the $\mathrm{Pr}^{3+}$ ions $[6,7]$.

Hereafter we present a site-selective excitation spectroscopy study of the ${ }^{3} \mathrm{P}_{0} \rightarrow{ }^{3} \mathrm{H}_{4}$ transition of $\operatorname{Pr}^{3+}$ ions in ion-exchanged sodium $\beta$-alumina crystals to provide further evidences for a different site occupancy of trivalent luminescent cations in the crystal structure of this host material.

\section{Experimental}

Single crystals of sodium $\beta$-alumina were provided by Union Carbide Corp. and by Ceramatech Inc. Their composition was $\left(\mathrm{Na}_{2} \mathrm{O}\right)_{1.23} \cdot 11 \mathrm{Al}_{2} \mathrm{O}_{3}$ and $\left(\mathrm{Na}_{2} \mathrm{O}\right)_{1.28} \cdot 11 \mathrm{Al}_{2} \mathrm{O}_{3}$, 
respectively. Small platelets of rectangular form (typical size: $2 \times 3 \times 0.5 \mathrm{~mm}^{3}$ ) were obtained from larger boules, and were ion exchanged with $\mathrm{Pr}^{3+}$ by immersion in molten $\mathrm{PrCl}_{3}$ under argon atmosphere [5,8]. The amount of the exchange was determined by electron probe microanalysis, which revealed degrees of exchange up to $95 \%$ for the sodium ions [5]. For the optical measurements the crystals were mounted into an optical cryostat, cooled by liquid $\mathrm{He}$, and the sample temperature was maintained below $10 \mathrm{~K}$.

Broad band excitation and emission spectra were excited using a $250 \mathrm{~W}$ Xe arclamp source filtered by a Jobin Yvon monochromator (mod. H.20, focal length of 200 $\mathrm{mm}$, equipped with a 1200 grooves/mm grating). A spectral resolution of $\sim 4 \AA$ was adopted for the excitation. The incident beam was focused onto the sample through a lens of $25 \mathrm{~cm}$ focal length. The fluorescence was analyzed at $90^{\circ}$ by a Jobin-Yvon double-monochromator (Ramanor, mod. HG2-S, focal lentgh of $1000 \mathrm{~mm}$, equipped with holographic gratings, 2000 grooves $/ \mathrm{mm}$, blazed at $514.5 \mathrm{~nm}$ ) and detected by a photon counting system, with a Peltier cooled photomultiplier (RCA, mod. C31034A$02)$. In this case the spectral bandpass was $\sim 1 \mathrm{~cm}^{-1}$ at $500 \mathrm{~nm}$ with $100 \mu \mathrm{m}$ slits. The advancement of both spectrometers was provided by step motors. A microcomputer was used to store the photon counts.

Polarized excitation spectra were recorded with the incident radiation perpendicular to the $\mathbf{c}$ axis of the crystal $\left(\mathbf{k}_{\text {inc }} \perp \mathbf{c}\right)$ and circularly polarized $(\sigma+\pi$ polarization). For the emission spectra a sheet polarizer allowed the collection of the radiation polarized perpendicularly to the plane of scattering, while the crystal orientation was changed so that the emission spectra were recorded with $\mathbf{E} \perp \mathbf{c}(\sigma)$ and $\mathbf{E} \| \mathbf{c}(\pi)$.

Finally, laser excitation of the $\mathrm{Pr}^{3+}$ ion in $\beta$-alumina crystals was obtained using the different lines of $\mathrm{a} \mathrm{Ar}^{+}$ion laser (Spectra Physics, mod. 161), while the remainder of the experimental apparatus was the same as for the broad band excitation described above.

\section{Results and discussion}

Typical $\sigma$ and $\pi$ polarized fluorescence spectra of a $60 \% \operatorname{Pr}^{3+}$-exchanged sodium $\beta$ alumina crystal, recorded at $10 \mathrm{~K}$ under broad band excitation within the ${ }^{3} \mathbf{P}_{2}-{ }^{3} \mathbf{P}_{1}\left({ }^{1} \mathbf{I}_{6}\right)$ region, are shown in Fig. 1 with an assignment of the different transitions observed. The emission lines from the ${ }^{3} \mathrm{P}_{0}$ level which terminate on the ${ }^{3} \mathrm{H}_{4},{ }^{3} \mathrm{H}_{5},{ }^{3} \mathrm{H}_{6}$ and ${ }^{3} \mathrm{~F}_{2}$ occur in the region between $21000 \mathrm{~cm}^{-1}$ and $15000 \mathrm{~cm}^{-1}$ and are characterized by strong inhomogeneous broadenings.

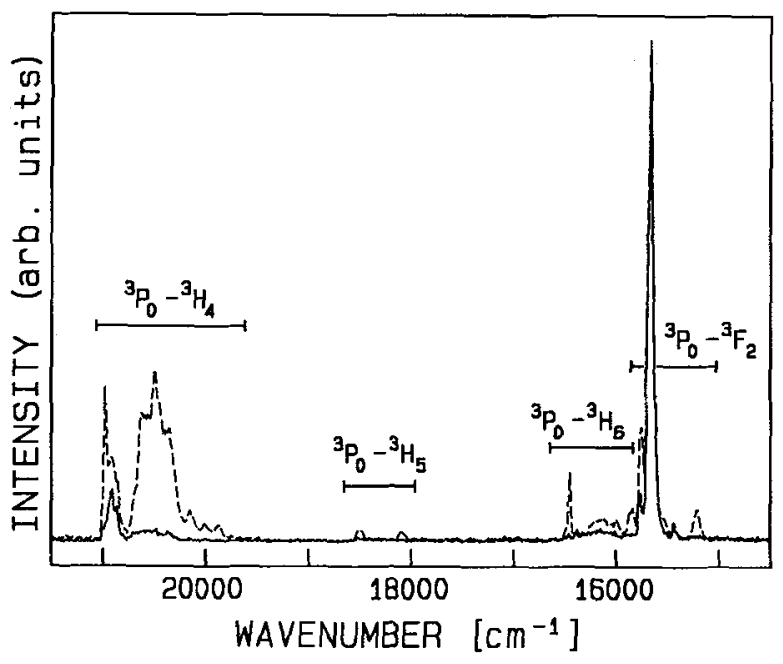

Fig. 1: Luminescence spectra obtained at $10 \mathrm{~K}$ from a $\mathrm{Pr}^{3+}$. exchanged $(60 \%) \quad \beta$-alumina crystal under broad band excitation at $457 \mathrm{~nm}$, in $\sigma$ polarization (continuous line) and in $\pi$-polarization (dashed line). 
Some $\sigma+\pi$ polarized excitation spectra, obtained under excitation of a Xe lamp from the same composition, are plotted in Fig 2. The spectra correspond to three different emission lines of the ${ }^{3} \mathrm{P}_{0}+{ }^{3} \mathrm{H}_{4}$ transition. The top (Fig. 2 a) and bottom (Fig. 2 c) spectra clearly originate from two different sets of centres: they have to be related to distinct occupied sites of $\operatorname{Pr}^{3+}$ ions in the conduction plane of $\beta$-alumina. Besides the peak positions, the most stricking differences are related to the width of spectral lines, which are inhomogeneous in character and indicate a different spread in the sitedistribution of each set of centres. The mid spectrum (Fig. 2 b) is mostly the superposition of the two spectra a and c, but some extra features are present. Apart from the peak at $\sim 454 \mathrm{~nm}$, it closely resembles the $\sigma$-polarized absorption spectrum of an 94\%-exchanged crystal, which has been reported elsewhere [6], where this peak appeared with a negligible intensity.

Fig. 2: Broad band excitation spectra of the ${ }_{3} \mathbf{P}_{0} \rightarrow{ }_{3} \mathbf{H}_{4}$ emission lines at: (a) $20586 \mathrm{~cm}^{-1}$; (b) $20503 \mathrm{~cm}^{-1}$; and (c) $20000 \mathrm{~cm}^{-1}$. The spectra were recorded at $10 \mathrm{~K}$ with $\mathbf{k}_{\text {inc }} \mathbf{c}$ in $\sigma+\pi$ polarization.

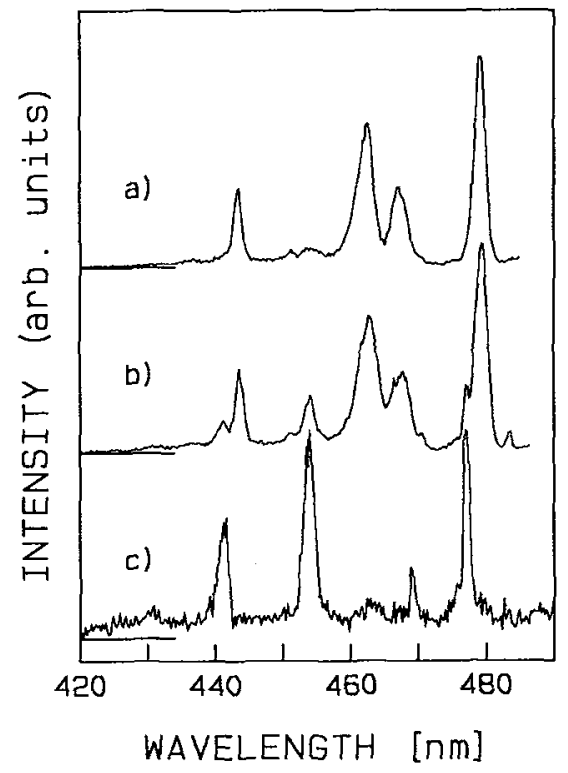

Very similar spectra, either in excitation or in emission, were obtained from crystals with lower $\mathrm{Pr}^{3+}$ ion contents.

The emission spectra of the ${ }^{3} \mathrm{P}_{0} \rightarrow{ }^{3} \mathrm{H}_{4}$ transition, excited at various wavelengths within the ${ }^{3 P_{2}}-3 P_{1}\left({ }^{1} I_{6}\right)-3 P_{0}$ region by a $\mathrm{cw} \mathrm{Ar}{ }^{+}$ion laser, show very complex structures with many, strongly polarized components in the region between $21000 \mathrm{~cm}^{-1}$ and $19800 \mathrm{~cm}^{-1}$. However, a quite satisfactory site-selective emission is achieved using proper excitation lines, as shown in Fig 3. In particular, the fluorescence spectra excited at $465.8 \mathrm{~nm}$ (Fig. 3 a) and $476.5 \mathrm{~nm}$ (Fig. $3 \mathrm{c}$ ), are mostly related to the two different sets of centres identified in Fig. $2 \mathrm{a}$ and c, respectively. These spectra, even if very structured due to the presence of several, partially overlapping components, indicate remarkable differences in the ground state splittings of their respective centres, which are roughly twice for the set preferentially excited at $476.5 \mathrm{~nm}$. Moreover, their peculiar polarization characters further confirm the different site occupancy by $\mathrm{Pr}^{3+}$ in the conduction plane of $\beta$-alumina. Finally, the spectra of Fig. $3 \mathrm{~b}$ contain the contributions from both sets of centers, thus correlating with Fig. 2 b.

\section{Conclusions}

Our excitation and emission study provide new indications of a different site occupancy of lanthanide ions in $\beta$-alumina crystals. It also shows that a satisfatory site-selective fluorescence from single sets of centres may be achieved under cw laser-excitation. 


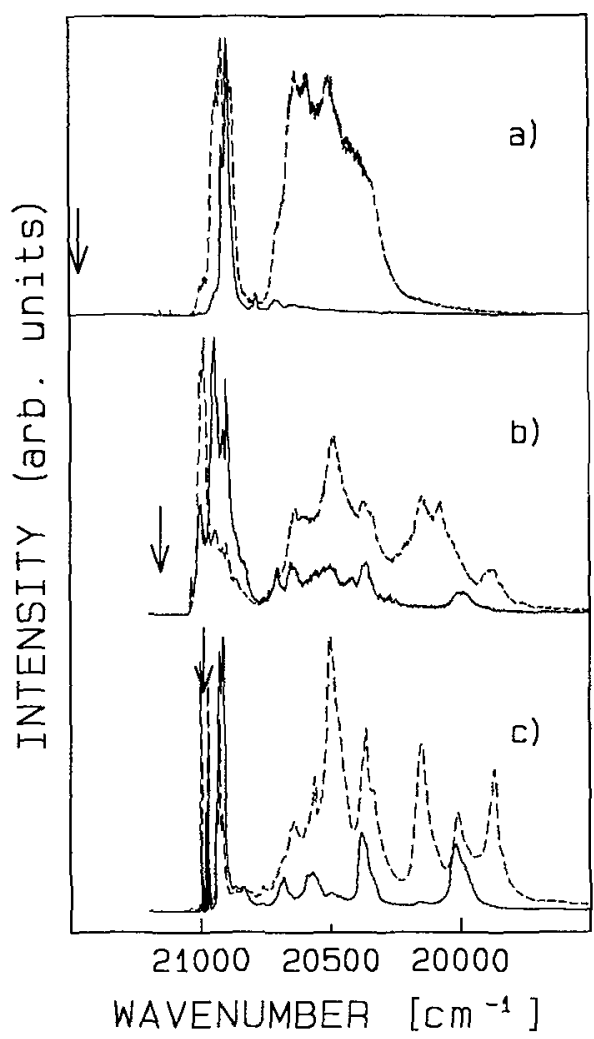

Fig. 3: ${ }^{3} \mathrm{P}_{0} \rightarrow 3 \mathrm{H}_{4}$ emission spectra in $\sigma$ polarization (continuous line) and in $\pi$ polarization (dashed line) of a $60 \%$ ionexchanged $\mathrm{Na}^{+} / \mathrm{Pr}^{3}+\beta$-alumina crystal at $10 \mathrm{~K}$ excited at $465.8 \mathrm{~nm}(\mathrm{a})$, at 472.7 $\mathrm{nm}(\mathrm{b})$ and at $476.5 \mathrm{~nm}$ (c) as indicated by the arrows.

\section{Acknowledgments}

One of us (F.T.) gratefully acknowlegdes the Alexander von Humboldt foundation for a Feodor Lynen grant. This work has been partially supported by the Consiglio Nazionale delle Ricerche, under contract No. 93.01312.CT02.

\section{References}

[1] G. C. Farrington, B. Dunn and J. O. Thomas, Cryst. Latt. Def. and Amorph. Mat. 12 (1985) 497.

[2] G. C. Farrington, B. Dunn and J. O. Thomas, in High Conductivity Solid State Conductors (Recent Trends and Applications), Ed. T. Takahashi (World Scientific, Singapore, 1989) pp. 327 - 365.

[3] G. Mariotto, in Fast Ion Transport in Solids, Eds. B. Scrosati, A. Magistris, C. M. Mari and G. Mariotto (Kluwer Academic Publishers, Dordrecht, 1993) pp. 41 - 67.

[4] M. Jansen, A. Alfrey, O. M. Stafsudd, B. Dunn, D. L. Yang and G. C. Farrington, Opt. Lett. 10 (1984) 119.

[5] F. Tietz and W. Urland, Solid State lonics 46 (1991) 331.

[6] F. Tietz, E. Zaghellini and G. Mariotto, Solid State Ionics, in print.

[7] G. Mariotto, F. Tietz, E. Zaghellini and M. Ferrari, J. Lumin., in print.

[8] F. Tietz and W. Urland, J. Alloys Comp. 192 (1993) 78. 